\title{
Note on Transliterations
}

Words transliterated from Arabic follow IJMES guidelines with modifications. Glottal stops 'ayn and hamza are preserved in most instances, and vowels and syllables have been added to enable ease of readability, particularly for nonspecialists. 
THIS PAGE INTENTIONALLY LEFT BLANK 
Competitive Archaeology in Jordan 
THIS PAGE INTENTIONALLY LEFT BLANK 